\title{
Dual excitation multi-fluorescence flow cytometry for detailed analyses of viability and apoptotic cell transition
}

\author{
G. Mazzini, C. Ferrari, ${ }^{1}$ E. Erba ${ }^{2}$ \\ Inst. of Molecular Genetics, Histochemistry and Cytometry CNR, Dept. of Animal Biology; ${ }^{1}$ Experimental \\ Surgery, Dept. of Surgery, University of Pavia; ${ }^{2}$ Dept. of Oncology, Flow Cytometry Unit, Mario Negri \\ Institute, Milan, Italy
}

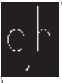

(C)2003, European Journal of Histochemistry

The discrimination of live/dead cells as well as the detection of apoptosis is a frequent need in many areas of experimental biology. Cell proliferation is linked to apoptosis and controlled by several genes. During the cell life, specific events can stimulate proliferation while others may trigger the apoptotic pathway. Very few methods (i.e. TUNEL) are now available for studies aimed at correlation between apoptosis and proliferation. Therefore, there is interest in developing new methodological approaches that are able to correlate apoptosis to the cell cycle phases. Recently new approaches have been proposed to detect and enumerate apoptotic cells by flow cytometry. Among these, the most established and applied are those based on the cell membrane modifications induced in the early phases of the apoptotic process. The dye pair Hoechst 33342 (HO) and Propidium lodide (PI), thanks to their peculiar characteristics to be respectively permeable and impermeable to the intact cell membrane, seems to be very useful. Unfortunately the spectral interaction of these dyes generates a consistent "energy transfer" from HO to PI. The co-presence of the dyes in a nucleus results in a modification in the intensity of both the emitted fluorescences. In order to designate the damaged cells (red fluorescence) to the specific cell cycle phases (blue fluorescence), we have tested different staining protocols aimed to minimize the interference of these dyes as much as possible. In cell culture models, we are able to detect serum-starved apoptotic cells as well as to designate their exact location in the cell cycle phases using a very low PI concentration. Using a Partec PAS flow cytometer equipped with HBO lamp and argon ion laser, a double UV/blue excitation has been performed. This analytical approach is able to discriminate live blue cells from the damaged (blue-red) ones even at $0.05 \mu \mathrm{g} / \mathrm{mL}$ PI. The same instrumental setting allows performing other multi-colour analyses including AnnexinV-FITC as well as the possibility to make a correlated analysis to phenotype markers.

Key words: Flow cytometry, Fluorescence microscopy, Apoptosis, Membrane damage, HO 33342, Cell culture.

Corresponding author: Giuliano Mazzini, Istituto di Genetica Molecolare del CNR, Sezione di Istochimica e Citometria, Piazza Botta 10, 27100 Pavia, Italy. E-mail: mazzi@igm.cnr.it

Paper accepted on July 30, 2003

European Journal of Histochemistry 2003; vol. 47 issue 4 [0ct-Dec]: 289-298
A poptosis can be studied taking into account many morphological and functional criteria including chromatin condensation and margination, cell shrinkage, formation of apoptotic bodies, etc. (Darzynkiewicz et al., 1992; van Engelans et al., 1998; Willingham, 1999; Necchi, 2000; Soldani et al. 2001; Bonanno et al., 2002; Kiechle et al., 2002). Fluorescence microscopy is playing an important role in these studies because many utilized probes are fluorochromes and others are on purpose labelled with fluorophores. In addition, morphological details guaranteed by phase contrast combined with fluorescence microscopy contributed to the unbeatable power of microscopy supporting and/or confirming data obtained by other techniques (biochemistry, molecular biology, flow cytometry etc.) (Uva et al., 2002; Chionna et al., 2003; Smetana et al., 2003). Flow cytometry, in particular, is playing an important role in these studies since large cell sample can be analysed in a short time with minimal cell manipulation and the possibility to study simultaneously multiple parameters (Pollice et al., 1992; Schmid et al., 1992; Douglas et al., 1998; Schmid et al., 1999; Casasco et al., 2001; Donahue et al., 2001).

Among different methods those based on the cell membrane permeability to fluorescent probes, are the most established and routinely used in many applications. The membrane status can be monitored either directly using specific probe like AnnexinV (van Engelans et al., 1998; Clarke et al., 2000) or indirectly via DNA binding fluorochromes (Telford et al., 1992; Frey, 1995; Zamai et al., 1996; Willingham, 1999). Permeability depends on the physico-chemical characteristics of the fluorochrome molecule and the function of the cell membrane. The so-called vital DNA dyes (e.g. Hoechst 33348 and 33342) can enter the intact membrane of viable cells while, for example, relatively large molecules of phenantridinic dyes (propidium iodide and ethidium bromide) can only penetrate seriously damaged membrane or 
dead-necrotic cells. $\mathrm{HO} 33342$ ( $\mathrm{HO}$ ) is definitely the most popular fluorochrome employed and remains as a landmark of nuclear staining used in fluorescence microscopy and flow cytometry (Loken, 1980; Crissman et al., 1990; Belloc et al., 1994; Boltz et al., 1994; Maciorowski et al., 1998; Boutonnat et al., 2000).

Several schools have contributed with data on the understanding the DNA staining behaviour of this fluorescent dye (Stöhr et al., 1980; Erba et al., 1988; Ellwart et al., 1990; Telford et al., 1992). In fixed cells $\mathrm{HO}$ is accessible to the chromatin and under condition of dye saturation, bound $\mathrm{HO}$ fluorescence is stoichiometrically related to the DNA content. In unfixed cell population the fluorescence of $\mathrm{HO}$ in the nuclei is mainly the function of two opposite events: the passive entrance of $\mathrm{HO}$ in the cell (modulated by the membrane physiology and permeability status) and its active exit modulated by a specific pumping system, powered by the cell metabolism.

Propidium iodide (PI) is also a very well established nuclear probe largely utilized in conventional (Mazzini et al., 1980) as well as in flow cytometry for DNA quantification (Crissman et al., 1973; Myc et al., 1992). Due to its physico-chemical characteristics it cannot enter the intact membrane of live cells. Therefore it is a valid candidate to be coupled with $\mathrm{HO}$ in a dual staining procedure suitable for studies of live-dead cell turnover. Several papers have been published on this dye couple and on their ability to identify dead/necrotic cells among a live population under different experimental conditions (Belloc et al., 1994; Boutonnat et al.2000). We also exploited the differential staining capability of $\mathrm{HO}$ in single staining as well as in combination with PI. In the framework of detailed cytokinetic studies of the effects induced on cell cultures by radiation treatments we focused on the possibility to identify damaged cells (apoptotic-necrotic) as well as their location on the corresponding cell cycle phase. This can actually be done by means of the TUNEL method aimed to label the DNA strand breaks. After fixation, cells have been stained by PI and the dual parameter green-red flow cytometry allowed the positioning of green labelled (damaged) cells along the cell cycle phases detailed by PI.

The disadvantages of the above approach (time consuming and expensive reagents) have pushed towards development of alternative simpler methods. In this paper, we describe a new methodological approach based on the simultaneous application of three widely applied fluorescent probes for studies on viable cells discrimination. The DNA histogram distribution is obtained by means of $\mathrm{HO}$ staining in stoichiometric condition while the assessment of the severity of membrane damage is assigned to PI combined with AnnexinV-FITC. We apply the power of dual excitation flow cytometry in order to excite each fluorochrome with the optimal spectral band. This particular instrumental setting guarantees minimal spectral interactions between $\mathrm{HO}$ and $\mathrm{PI}$. Keeping the concentration of the latter probe very low, we could limit the energy transfer from $\mathrm{HO}$ to PI. This resulted in nearly undistorted DNA profile generated by the $\mathrm{HO}$ fluorescence.

\section{Materials and Methods}

CEM cell line was grown in suspension in RPMI1640 medium supplemented with 10\% FBS, 2 mM glutamine, $100 \mathrm{U} / \mathrm{mL}$ penicillin and $100 \mu \mathrm{g} / \mathrm{mL}$ streptomycin. DHD K12 TRb (DHD) cell line, was grown as monolayer in HAM'S F10 and DMEM supplemented with $10 \%$ FCS, 1 mM glutammine and $40 \mu \mathrm{g} / \mathrm{mL}$ gentamicine. The monolayer was harvested using a solution containing $0.05 \%$ trypsin and $0.5 \mathrm{mM}$ EDTA.

Both cell lines were maintained at $37^{\circ} \mathrm{C}$ in a humidified atmosphere with $5 \% \mathrm{CO}_{2}$. The cells were Mycoplasma-free throughout the study.

We have induced cell death by withdrawing serum from the culture medium when $60-70 \%$ confluence was reached. We preliminary checked, on both cultures, the FCS-free time needed for induction of apoptosis.

\section{Reagents}

A stock solution of HO (Sigma B 2261) had been prepared at a concentration of $1 \mathrm{mg} / \mathrm{mL}$ and maintained at $4^{\circ} \mathrm{C}$ in the dark. At the time of experiments two different staining solutions have been prepared for non saturating conditions as well as for saturating staining. The first one had been performed with $\mathrm{HO} I \mu \mathrm{g} / \mathrm{mL}$ diluted directly in the culture medium or in phosphate buffer saline (PBS). For saturating staining a concentration of $\mathrm{HO}$ equivalent to 5 $\mu \mathrm{g} / \mathrm{mL}$ have been prepared adding the stock solution directly into the culture medium.

A stock solution of PI (Sigma P 4170) in distilled water had been prepared at a concentration of 0.5 $\mathrm{mg} / \mathrm{mL}$ and stored at $4^{\circ} \mathrm{C}$ in the dark. According to different staining protocols the final concentration 
utilized ranged from $5 \mu \mathrm{g} / \mathrm{mL}$ down to $0.05 \mu \mathrm{g} / \mathrm{mL}$. Annexin $\mathrm{V}$ labelled with fluoresceine isothiocianate (AnnexFITC) (Euro Clone EIKI00F) had been used at a concentration of $1.5 \mu \mathrm{g} / 10^{6}$ cells. Counter-staining with PI had been performed using a concentration of $1 \mu \mathrm{g} / \mathrm{mL}$.

\section{Instrumentation}

\section{Fluorescence microscopy}

Samples have been observed by means of an Olympus BX51 microscope with standard fluorescence equipment: 1) ultraviolet excitation: BP 330385 nm, DM 400 and barrier filter BA 420;2) blue excitation: BP 450-480, DM 500 and barrier filter BA 515. Objectives UVPlanFI 20X (0.50), UVPlanFI 40X (0.75) and Plan 40X (0.65) Ph have been routinely used. The UPC-D condenser allowed the bright as well as the phase contrast field settings. Fluorescence microphotographs were taken using an Olympus C35AD4 camera equipped with Kodak Elite Chrome 100 slide film.

\section{Flow cytometry}

A flow cytometer Partec PAS equipped with two excitation sources: 1) argon ion laser $20 \mathrm{~mW}$ output power at $488 \mathrm{~nm}$ and 2) HBO $100 \mathrm{~W}$ mercury arc lamp. UV excitation (BP 350-390 nm, DM 400, LP 420) as well as sequential dual correlated excitation (UV and $488 \mathrm{~nm}$ blue line) were employed. Data handling was performed by FlowMax software from the same Company.

\section{Methods}

CEM cells grown in suspension are stained directly in their growth medium. DHD adherent cells harvested, washed and re-suspended in their growth medium were mixed with the corresponding cells recovered from the surnatant. All cell suspensions are prepared taking into account a cell concentration of approximately $1 \times 10^{6} \mathrm{cell} / \mathrm{mL}$ medium. At the end of staining all samples have been observed by fluorescence microscope and analyzed by flow cytometry directly in the staining solution without any preliminary washing.

\section{HO staining, non saturating mode}

Two milliliters of cell suspension are placed in a 5 $\mathrm{mL}$ plastic tube and $\mathrm{HO}$ stock solution is added to have a final concentration of $1 \mu \mathrm{g} / \mathrm{mL}$. Tubes are kept at room temperature $\left(20^{\circ} \mathrm{C}\right)$ for $30 \mathrm{~min}$.
Samples are split in two aliquots: the first one (few $\mu l$ ) is deposed on a glass slide for fluorescence microscopy while the rest is used for flow cytometry.

\section{HO staining, saturating mode}

Cell suspensions ( $1.5 \mathrm{~mL}$ ) are placed in a $2 \mathrm{~mL}$ polypropilene conical plastic tube and $\mathrm{HO}$ is added in order to have a final concentration of $5 \mu \mathrm{g} / \mathrm{mL}$. The tube is placed in a temperature-controlled plate (Multi-Block Heater LAB-LINE Instruments, IL, USA) at $40^{\circ} \mathrm{C}$ for $5 \mathrm{~min}$ and then on cold ice bath $\left(0^{\circ} \mathrm{C}\right)$ for further $5 \mathrm{~min}$. After staining an aliquot of cell suspension is placed on a glass slide for microscopic observation while the rest is used for flow cytometry.

\section{Double staining with $\mathrm{HO}-\mathrm{PI}$}

After staining with $\mathrm{HO}$ (both non- and saturatingconditions) samples are counter-stained with PI by just adding a proper quantity of PI stock solution directly in the cell suspension previously stained with $\mathrm{HO}$ (without any washing procedure). Two different PI concentration have been tested respectively named normal and low. In normal staining, $20 \mu \mathrm{l}$ of PI stock had been added to $2 \mathrm{~mL}$ of sample equivalent to a final concentration of $5 \mu \mathrm{g} / \mathrm{mL}$. For low staining procedure, we have diluted the PI stock solution 1:100 in distilled water and added $20 \mu \mathrm{L}$ of this dilute PI to each sample. This resulted in a final concentration of $0.05 \mu \mathrm{g} \mathrm{PI} / \mathrm{mL}$. Tubes are maintained in the dark at room temperature for $5 \mathrm{~min}$. Samples have been observed by a fluorescence microscope and analyzed by flow cytometry directly in the staining solution.

\section{Triple staining with HO-PI-AnnexFITC}

Samples already stained with $\mathrm{HO}$ in saturating mode are processed according to a standard protocol for Annexin $\vee$ labelling. Samples are centrifuged and re-suspended in $2 \mathrm{~mL}$ binding buffer (included in the kit) containing $5 \mu \mathrm{g} / \mathrm{mL} \mathrm{HO}$ and stored in the dark at room temperature for 5 min. After addition of $3 \mu \mathrm{l}$ of AnnexFITC solution to each sample, the sample was gently shaken. Twenty $\mu \mathrm{L}$ of dilute PI solution (as described for PI low concentration) was added. The sample was allowed to stand for $10 \mathrm{~min}$ at room temperature in the dark. Samples were used for fluorescence microscopy as well as for flow cytometry without any washing procedure. 

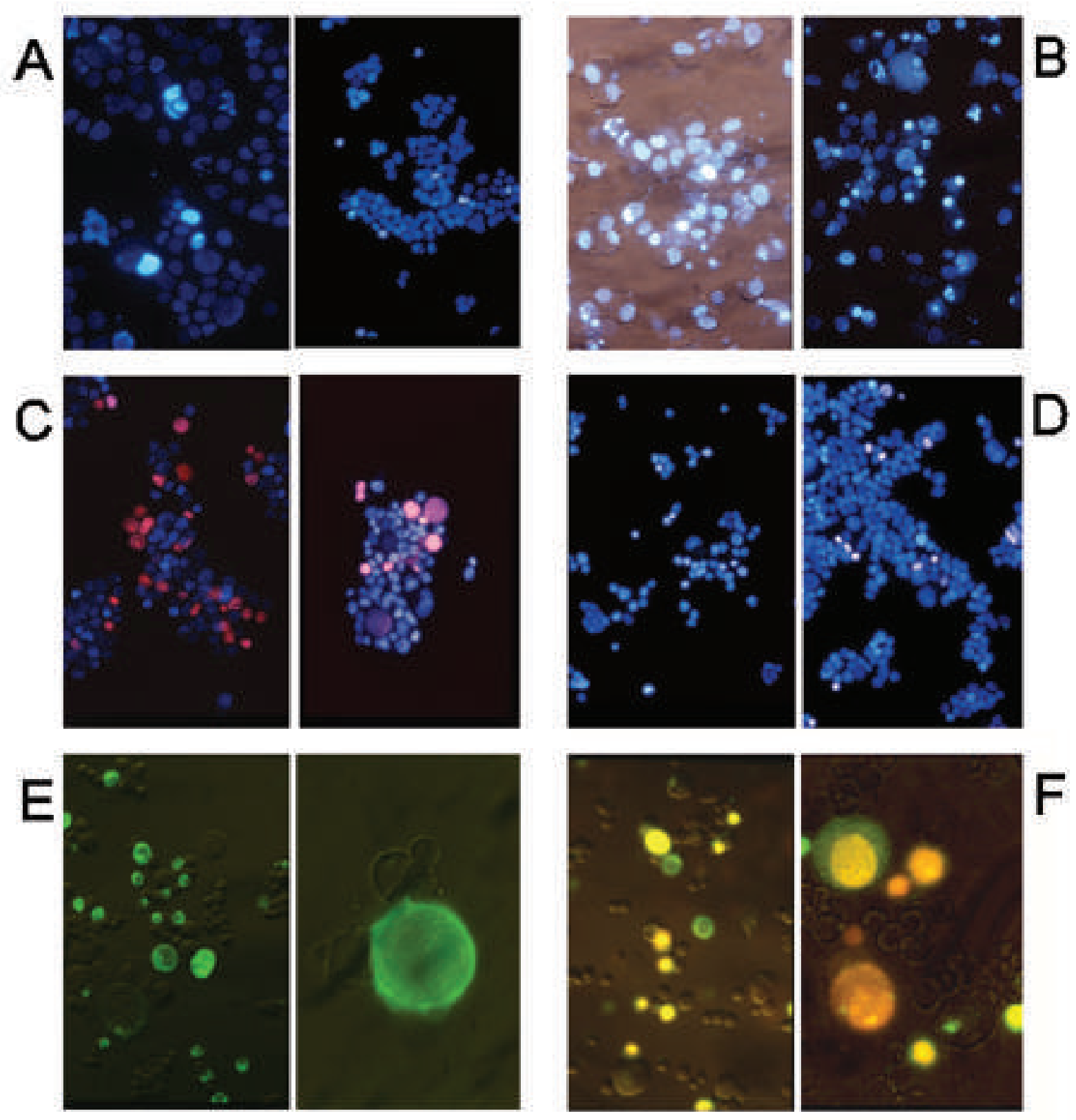

Figure 1. Fluorescence pictures of DHD cells treated according to various staining protocols (A-F). Cell samples obtained by a proper mix of an aliquot of adherent cells (prevalently live and healthy) harvested from the culture flask and the cells recovered by centrifugation of the supernatant (prevalently damaged necrotic-apoptotic) of the same flask. All cell samples have been stained in suspension, spun down and deposited onto glass slides. Observations and pictures have been taken without any washing and without addition of anti-fading agents. A) Staining with $\mathrm{HO}$ alone under non saturating condition. Live and healthy cells are faintly blue stained, while the damaged/apoptotic are more bluish-white. B) Phase contrast-fluorescence of a sample enriched with dead cells. A large number of morphologically altered cells representing various steps of apoptosis and/or necrosis is evident. Same staining protocol as previous figure. C) Double staining with HO under non saturating condition and various concentrations of $\mathrm{PI}(5 \mathrm{and} 1 \mu \mathrm{g} / \mathrm{mL}$ from left to right). Sample allows seeing slightly damaged cells only stained by HO (from faint to bright blue) while those more severely damaged (with membrane permeable also to PI) emit pink to red fluorescence, depending on the ratio of $\mathrm{HO} / \mathrm{PI}$ in their chromatin. The fluorescence emission is strongly altered by the energy transfer from HO to PI. (See discussion for further details). D) Double staining with HO under saturating condition and low concentration of PI. Sample shows majority of nuclei fluorescent brilliant blue (emission intensity stoichiometrically related to the DNA content). Few damaged cells show whitish-pink nuclei stained by both dyes. E) Phase contrast-fluorescence of AnnexFITC stained cells. Unstained live cells together with various degree of damaged cells labelled with light as well as bright green fluorescence are evident. Higher magnification (right) shows the green fluorescence located on the cell membrane. F) Double staining with AnnexFITC and PI. Phase contrast-fluorescence shows a very detailed picture of live-dead cells from completely unstained to various degree of single as well as double labelling. It is possible to note very early apoptotic figures green labelled as well as necrotic cells or isolated nuclei only red labelled by PI. 

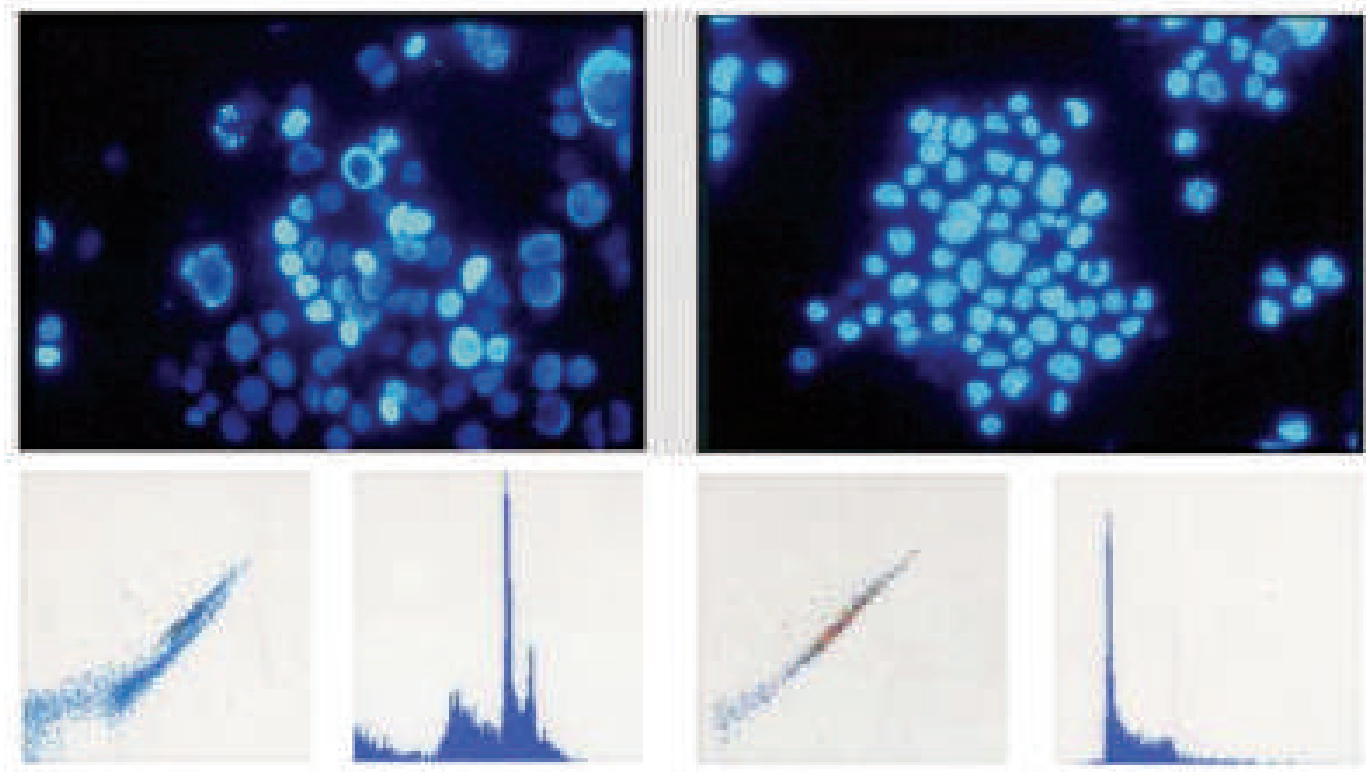

\begin{abstract}
Figure 2. DHD cells stained with HO under non saturating mode (left) and under saturating staining condition (right). Different dye uptake is evident under UV excitation. Live and healthy cells appearing faint blue and the damaged (apoptotic and/or necrotic) appearing brighter and bluish white (left). By increasing the staining temperature and dye concentration a condition of saturation is reached and all nuclei become brightly fluorescent. The corresponding flow cytometry data plots are reported below. The DNA histogram obtained by HO staining under saturating condition (right) displays the proliferative profile of the culture. The dual parameter (red-vertical vs blue-horizontal) correlated analysis (left) of cells stained under non saturating condition allow differentiating a brighter sub-population (shifted to the red axis) corresponding to the damaged cells.
\end{abstract}

\section{Results}

\section{HO staining, non saturating mode}

Cell suspension stained by $\mathrm{HO}(1 \mu \mathrm{g} / \mathrm{mL})$ at room temperature observed under UV excitation show a heterogeneously stained nuclei: the majority are faint blue while some appear brighter. The colour of the emission is also changed: the less intense are bluish, while the brighter ones turn white/yellow (Figure 1A). These differences are more evident when the cell suspension is obtained after trypsin treatment of DHD as compared to CEM cell line. When the cells recovered from the supernatant are stained separately the majority of nuclei (other than those diagnosed evidently damaged by their morphology) are white/yellow and very few cells show a faint blue fluorescence (Figure 1B). Flow cytometry of these samples (single UV excitation) analysed as single emission above $420 \mathrm{~nm}$ show a very heterogeneous distribution of fluorescence intensity. When fluorescence is split into two bands ("blue" 420-500 $\mathrm{nm}$ and "red" above $500 \mathrm{~nm}$ ) generates a correlated plot, where two sub-populations become evident being the more fluorescent moved up (Figure 2 left bottom). Counter-staining with PI $(5 \mu \mathrm{g} / \mathrm{mL})$ turns the white/yellow nuclei to pink, while the faint blue remained unchanged (Figure $1 \mathrm{C}$ ).

\section{HO staining, saturating mode}

Cell suspension incubated with $\mathrm{HO}(5 \mu \mathrm{g} / \mathrm{mL})$ at $40^{\circ} \mathrm{C}$ observed by fluorescence microscopy, under UV excitation appears homogeneously stained (Figure 2 right upper). All nuclei exhibit a white/blue fluorescence very likely depending on their DNA content. No significant differences are noted according to the type of cell culture. Flow cytometry of the same samples allows obtaining a strict correlation between fluorescence intensity and DNA amount. The DNA histogram (Figure 2 right below) clearly represents the exponentially cycling profile of the culture. The correlated plot of the two fluorescence bands also show a linear increase of both signals without any apparent sub-population. Counter-staining of the samples with PI showed part of the nuclei changing fluorescence emission from white/blue to pink due to the interference of the red emission of PI (Figure 1D). Flow cytometry of double stained sample identify the sub-population of PI stained cells. These moved to the left in both single parameter DNA histogram as well as in the dual parameter plot (Figure 3). 

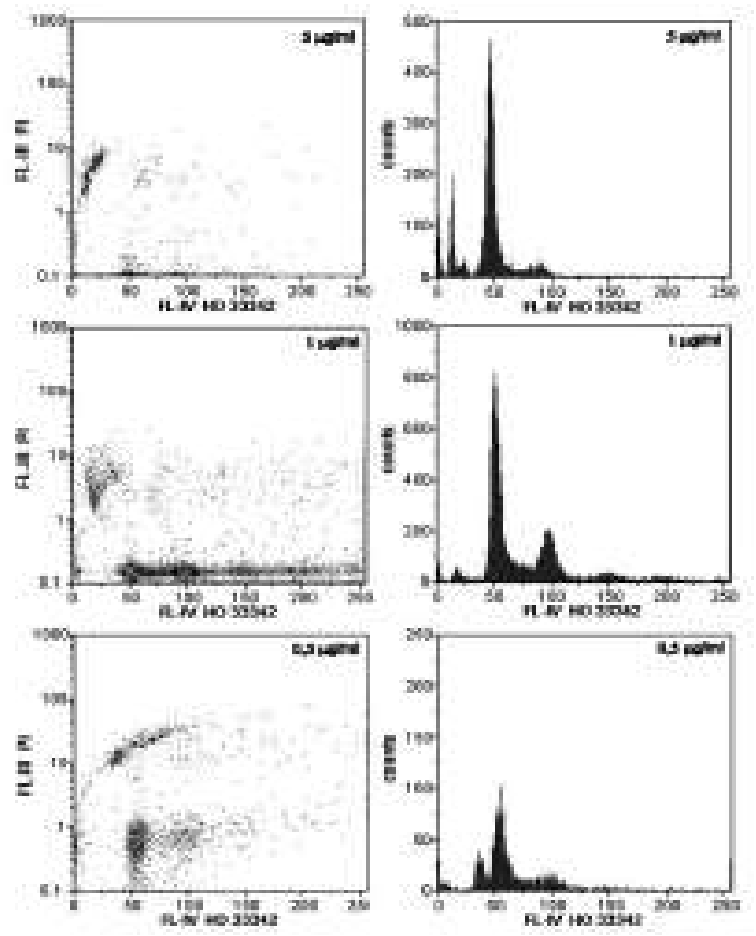

Figure 3. CEM cells double stained by $\mathrm{HO}$ under saturating condition and $\mathrm{PI}$ at three different concentrations: $5 \mu \mathrm{g} / \mathrm{mL}$ (upper), $1 \mu \mathrm{g} / \mathrm{mL}$ (middle) $0.5 \mu \mathrm{g} / \mathrm{mL}$ (lower). Left panels report the dual parameter correlated analyses of red (PI) fluorescence (vertical axis) versus blue (HO) fluorescence (horizontal axis). Right panels report the corresponding DNA histogram derived by the blue fluorescence. At the highest PI concentration (upper row) the double-labelled HO/PI sub-population is evidently shifted to the left due to the energy transfer effect from $\mathrm{HO}$ to PI. This effect is progressively reduced (middle and lower rows) when PI concentration is lowered to 0.5 $\mu \mathrm{g} / \mathrm{mL}$.

\section{AnnexFITC labelling}

Cell suspension treated with the standard protocol for single AnnexFITC staining observed by fluorescence microscope under blue excitation showed some brilliant green cells. Microscopic observation under phase contrast/fluorescence (Figure IE) showed that a large part of cells remained unlabelled. Flow cytometry performed by single laser excitation at $488 \mathrm{~nm}$ allowed discriminating and counting the AnnexFITC-positive cells from the negative ones. Counter-staining with PI allowed separation of the cell population into unlabelled, green labelled, red labelled and double labelled with both dyes (Figure $1 F$ ). Flow cytometry in dual parameter (green, red) plot allows counting of the three cell fractions separately (Figure 4 ).

\section{Triple staining with HO-PI-AnnexFITC}

Cell suspensions already stained with $\mathrm{HO}$ in satu-
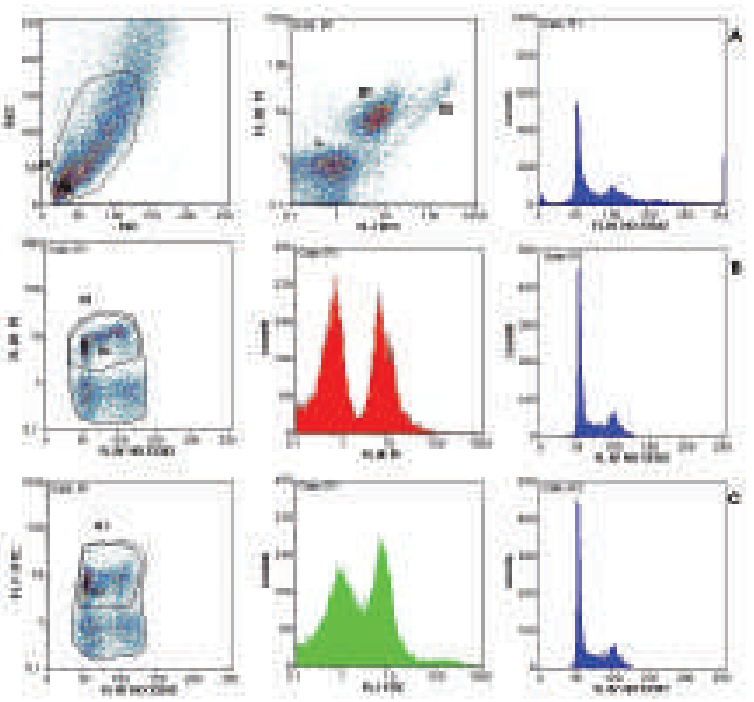

Figure 4. CEM cells sequentially stained with $\mathrm{HO}$ under saturating condition, AnnexFITC and PI followed by dual excitation flow cytometry. Acquired events are gated (R1) on the basis of scatter signals (SSC-FSC) as reported in the panel A left. By correlated analyses of green (AnnexFITC) and red (PI) signals generated by the laser excitation, live unlabelled cells (L) are distinguished from the labelled damaged ones (d1-d2). The corresponding DNA profile of the total cell population analysed is reported A-right. Data reported on rows $B$ and $C$ respectively refer to the red and to the green-labelled cell subpopulations. Middle panels report the distribution of red (B) and green (C) signals allowing differentiation of the respective positive/labelled cell fractions (right peaks) over the unlabelled ones (left peaks). Left panels report the correlated blue (HO) fluorescence versus red (PI) (B) and versus green (AnnexFITC) (C). R2 region represents the gated areas corresponding to the specific labelled subpopulations that generate the corresponding DNA profiles reported in B- and C-right.

rating mode and counter-stained with double AnnexFITC/PI protocol under microscope UV excitation show majority of the nuclei white/blue and a few white/pink (Figure 6-upper). The same field, when excited by blue light shows pink nuclei turned to red and some of these cells are also labelled by AnnexFITC (Figure 6 below). Very few cells are only green labelled.

Flow cytometry performed by dual UV/blue excitation allows the optimal stimulation of all the three fluorochromes involved. This approach allowed the possibility to perform correlated analysis of the three fluorescent signals acquired. In particular, the dual parameter plot of blue against red fluorescence allows to identify a red-labelled sub-population moved up the unlabelled one. This latter is clearly distributed according to the DNA histogram profile of the original cell culture. Plotting the blue against the green fluorescence, it is possible to identify the 


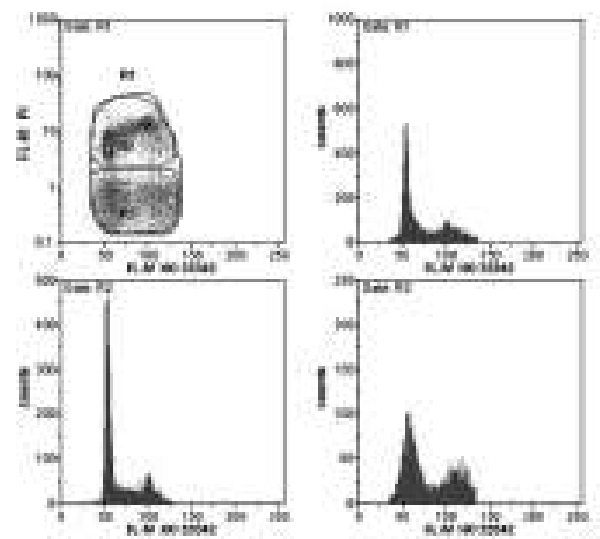

Figure 5. By the correlated dual parameter blue versus red fluorescence (upper left panel) three regions R1, R2 and R3 are defined representing respectively total acquired cells, red-PIlabelled and un-labelled cells. Same sample and measurement setting as reported in Figure 4. The corresponding DNA profiles can be derived easily representing respectively the total R1 population (upper right), the $\mathbf{R} 2$ red- labelled- damaged sub-population (lower left) and the R3 unlabelled- live subpopulation (lower right). Similar data should be drawn considering the green instead of the red fluorescence.

FITC-labelled cells distributed along the DNA histogram generated by the $\mathrm{HO}$ signal (Figure 4).

\section{Low PI concentration}

Similar experiments were performed with PI counter-staining at concentrations down to the limit of the sensitivity of the flow cytometer $(0.05$ $\mu \mathrm{g} / \mathrm{mL}$ ). This allowed minimizing the spectral interaction between $\mathrm{HO}$ and PI. At this very low concentration of PI, the red fluorescence emitted by the nuclei resulted very weak. The argon ion laser (488 $\mathrm{nm}$ ) of the flow cytometer, however, is able to excite the dye more efficiently. This allowed the red signals to be easily measured (Figure 5). The dual parameter plot of blue against red fluorescence allows the identification of red-labelled cell population, located in the upper part of the dot plot. We are able to show that this sub-population is now aligned with the corresponding unlabelled ones.

\section{Discussion}

Apoptosis can be studied by a large variety of methodological approaches, including morphology observed by fluorescence as well as by phase contrast microscopy. Unfortunately, most of the morphological changes (chromatin condensation, and margination, cell shrinkage, membrane blebbing and formation of apoptotic bodies) lack accurate features mak- ing quantification difficult and imprecise. On the other hand, flow cytometry had demonstrated, in this last decade, to be the analytical tool of choice for this kind of investigations (Darzynkiewicz et al., 1992; Frey, 1995; Ormerod et al., 1993; Vermes et al., 2000; Ormerod, 2002). A combination of visual observation (under fluorescence microscope) followed by flow measurement is a valid and unbeatable approach allowing the best interpretation of the results. This paper deals with development of a multiparametric approach based on flow cytometry with parallel observations by fluorescence and phase contrast microscopy for method validation.

As a model we have employed two different cell cultures, one grown in suspension (CEM) and the other (DHD) as a monolayer. The latter had been particularly useful as it offered the possibility to separately analyse both the supernatant cell fraction as well as the adherent one. In order to increase the number of apoptotic cells, the cells were cultured for a pre-established time in the serum-deprived medium. We have preliminary verified the presence of apoptotic cells by means of the well established methodology of AnnexFITC labelling (Figure 1E), alone and in combination with PI (Figure IF). From these pictures the presence of a significant fraction of apoptotic/necrotic cells in the culture becomes evident. In the case of DHD cells, we had been able to analyse separately the cell fraction recovered from the culture medium. These cells are prevalently dead with various degrees of morphological alterations from slightly damaged cell membranes to nude nuclei. Many typical figures of apoptosis like fragmented nuclei and characteristic apoptotic bodies are evident.

The capacity of $\mathrm{HO}$ to depict the different morphological and functional conditions of a cell is really very impressive. In particular, the metachromatic behaviour (Ellwart et al., 1990) of this fluorochrome allows differentiating light blue from white-yellow respectively as low- and high- concentration of the dye in the stained chromatin structure. $\mathrm{HO}$ penetrates into the living cells but is partially actively pumped out resulting in a faintly stained nucleus. On the contrary, cells with a damaged membrane cannot benefit of the pumping-out process. Thus the result is a more intense chromatin staining. In this case the corresponding fluorescence emission is bluish-white as compared to faint blue of the previous one (Figure $1 A, B$ ).

Cells harvested from the monolayer are (immedi- 

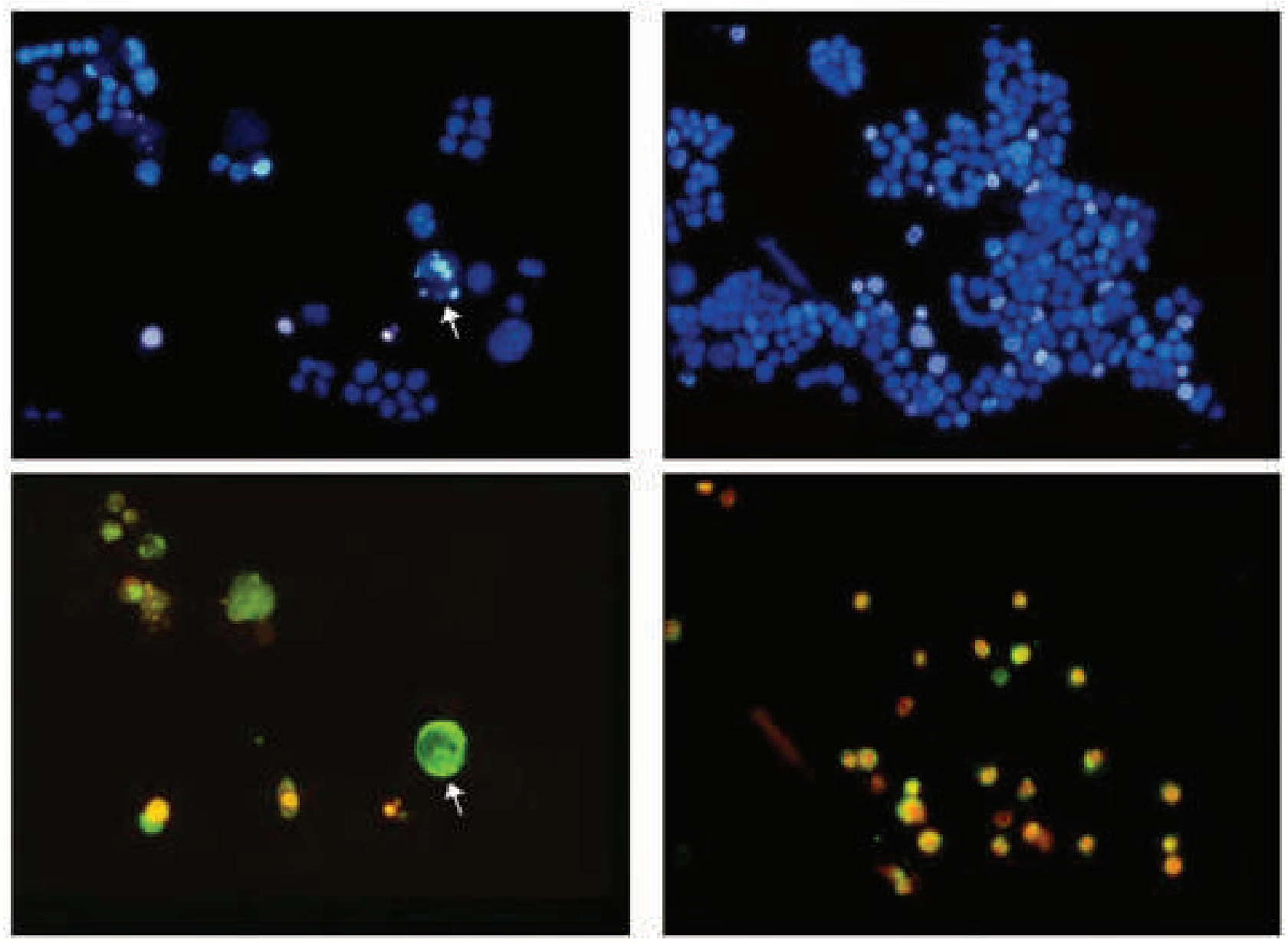

Figure 6. Two examples (left and right) of triple stained (HO-AnnexFITC and PI) DHD cells. Pictures have been taken using the same microscopic field first excited by blue light (lower panels) and then by UV (upper panels) to reduce photo bleaching of FITC-labelled cells. Very detailed description of various levels of multi-labelling can be derived (by combined UV and blue images), corresponding to different morphological and functional states of the cells. Intact live cells appear only HO- (blue) stained while damaged apoptotic cells are also green labelled. Severely damaged, likely late apoptotic-necrotic cells, are multi-labelled depending upon their membranes permeability to PI. Very peculiar is the behaviour of the arrow marked cells showing the nucleus already broken into several apoptotic bodies. The cell membrane is strongly labelled by AnnexFITC but still maintains its non-permeability to PI.

ately upon harvest) prevalently viable. We have tried to identify them by $\mathrm{HO}$ as well as by PI (data not shown) staining directly the adherent cells onto the Petri dish surface. Observing (20X magnification) the Petri dish surface under the fluorescence microscope we have identified very few brilliant (damaged) cells, prevalently at the margin of the growing area and in several points of over-confluence. Therefore we had been able to analyse separately the two cell fractions as well as to prepare a mixture of the two (coming from different pooled flasks) fractions in order to set up an experimental "artificial standard" cell suspension containing an high aliquot of damaged cells.

CEM line had been less versatile for two reasons: 1) due to its culture mode (in suspension) it did not allow the availability of separated aliquots of prevalently healthy and damaged cells; 2) depending on the slight morphological differences associated to the transition of live-dead in this cell model. For this reason, microphotographs are exclusively referring to DHD cells (Figures $1,2,6$ ). The CEM cells had been only dedicated to flow cytometry study (Figures $3,4,5)$.

For stoichiometric DNA staining, $\mathrm{HO}$ had been added directly into the culture medium for $5 \mathrm{~min}$ at $40^{\circ} \mathrm{C}$. Staining at $37^{\circ} \mathrm{C}$ had been reported (Crissman et al., 1990) to be the most important step in order to achieve acceptable coefficient of variation of the DNA measurement. We have found, however, that the DNA stainability (i.e. time and $\mathrm{HO}$ concentration) is strongly dependent on the type of cell culture. 
Therefore, we had to establish the optimal staining protocol to be applied in our experimental system. We also found that the staining kinetic of viable cells is strongly temperature-dependent. Increasing the incubation temperature by a few degrees results in a very rapid HO uptake and DNA saturation is achieved within minutes. This in our system worked as the best staining protocol that minimized cytotoxicity and guaranteed stoichiometric staining.

Toxicity of the DNA probes is always a problem and depends on the specific cell type (Erba et al., 1988; Siemann et al, 1986). It is crucial to keep toxicity as low as possible in case of "vital" staining. Fortunately, $\mathrm{HO}$ toxicity in our experimental systems becomes evident hours after exposure. As far as concentration is concerned, a range between 1 and 10 $\mu \mathrm{g} / \mathrm{mL}$ medium had been tested using staining times from 1 to $10 \mathrm{~min}$. The best condition $\left(5 \mu \mathrm{g} / \mathrm{mL}, 5^{\prime}\right)$ defined and later employed for the final multi-colour staining seems to be a good compromise between acceptable quality of DNA histogram and very limited number of damaged cells in the sample. The coefficient of variation ( $C V$ ) of the $G_{0 / 1}$ peak was around $6 \%$. This value is generally accepted for the cell cycle phase analysis.

As far as the potential immediate damage induced by $\mathrm{HO}$ staining is concerned, on both cell cultures, we tested the percentage of AnnexFITC/PI-positive cells before and after incubation with $\mathrm{HO} 5 \mu \mathrm{g} / \mathrm{mL}$ for $5 \mathrm{~min}$ at $40^{\circ} \mathrm{C}$. We did not observe variation higher than $10 \%$ of the original value thus concluding that $\mathrm{HO}$ induced cell damage is negligible on the overall handling of our cell samples.

It must be appreciated that adherent growing cells must be re-suspended in a medium to be analysed by flow cytometry. Harvesting/trypsinization mode is a crucial step causing itself cell damage. Mild trypsinisation and gentle treatments allow keeping this false damage factor down to 10-15\%. Obviously, cells growing in suspension are free of this drawback.

As far as the dual staining HO/PI is concerned, this couple of dyes represents quite a peculiar model for spectrofluorometric interactions. In the double stained nuclei the dyes are bound in very close proximity, so that when excited by UV the energy transfer takes place from $\mathrm{HO}$ to $\mathrm{PI}$, yielding a very evident effect (clearly demonstrated in Figure 3). Briefly, the energy captured by the $\mathrm{HO}$ molecules, instead of being released as fluorescence emission, is transferred to a very close PI molecule. Thus under fluo- rescence microscope we can see (in the double labelled nuclei) a reduction of blue emission and a corresponding enhancement of the red ones (Figure 1C). By flow cytometry the final effect of this interaction is clearly evident (Figure 3 ). The single $\mathrm{HO}$ labelled nuclei contributes to create the normal DNA histogram while the double HO/PI labelled ones are located in the upper/left correlated dual parameter plot.

As it has been reported by other authors (Bottiroli et al., 1994), this interaction can be useful: i.e. for the exclusion of dead cells from the remaining population to be studied (as in the case of phenotype assessment). In our case the final goals of the proposed methodology are to enumerate the damaged cells and to ascertain their location in the specific cell cycle phases. Therefore it is fundamental to be able to precisely evaluate the DNA content of both intact live ( $\mathrm{HO})$ as well as damaged (HO-PI) cells (Figure 5). In order to achieve this, we have tried to reduce the dyes interaction as much as possible. First, thanks to the dual excitation performed by the instrument we used, each dye was excited by a proper wavelength, thus providing excellent sensitivity. Second, we have reduced, to the limit of instrumental detection, the PI concentration thus keeping the energy transfer from $\mathrm{HO}$ to $\mathrm{PI}$ to a minimum. By using this experimental setting we had been able to obtain, on the same plot, the DNA distribution of the surviving population as well as that of the apoptotic/necrotic cells. The latter was further characterized by the third fluorochrome, AnnexFITC.

Application of this analytical approach in studies aimed to the evaluation of cytokinetic effects of new chemotherapeutic agents would be very helpful.

\section{Acknowledgements}

The authors thanks Sen Soumitra for helpful discussions and paper revision, Anna Maria Clerici for excellent technical assistance with cell cultures and the expertise of Cristiana Soldani for pictures editing. We are also indebted to Wolfgang Göhde junior who significantly contributed with his knowledge in dual excitation flow analyses.

\section{References}

Belloc F, Dumain P, Boisseau MR, Jalloustre C, Reiffers J, Bernard P, Lacombe F. A flow cytometric method using Hoechst 33342 and propidium iodide for simultaneous cell cycle analysis and apoptosis determination in unfixed cells. Cytometry 1994;17: 59-65.

Boltz RC, "Dutch" Fisher PA, Wicker LS, Peterson LB. Single UV excitation of Hoechst 33342 and ethidium bromide for simultaneous cell 
cycle analysis and viability determinations on in vitro cultures of murine B lymphocytes. Cytometry 1994;15:28-34.

Bonanno E, Tagliafierro G, Carlà EC, Montinari MR, Pagliara $P$, Mascetti G, Spagnoli LG, Dini L. Synchronized onset of nuclear and cell surface modifications in $\mathrm{U} 937$ cells during apoptosis. Eur J Histochem 2002;46:61-74.

Bottiroli G, Croce AC, Pellicciari C, Ramponi R. Propidium iodide and the thiol-specific reagent DACM as a dye pair for fluorescence resonance energy transfer analysis: an application to mouse sperm chromatin. Cytometry 1994, 15:106-16.

Boutonnat J, Barbier M, Muirhead K, Mousseau M, Grunwald D, Ronot $X$, Seigneurin, D. Response of chemosensitive and chemoresistant leukemia cell lines to drug therapy: simultaneous assessment of proliferation, apoptosis, and necrosis. Cytometry (Communications in Clinical Cytometry) 2000;42:50-60.

Casasco A, Casasco M, Cornaglia AI, Zerbinati N, Mazzini G, Calligaro A. Cell kinetics in a model of artificial skin. An immunohistochemical and flow cytometric analysis. Eur J Histochem 2001;45:125-30.

Chionna A., Panzarini E., Pagliara P.,De Luca A., Caforio S., Abbro L. Dini L. Hepatic clearance of apoptotic lymphocytes: simply removal of waste cells? Eur J Histochem 2003; 47:97-104.

Clarke RG, Lund EK, Johnson IT, Pinder AC. Apoptosis can be detected in attached colonic adenocarcinoma HT29 cells using annexin $\mathrm{V}$ binding, but not TUNEL assay or sub-GO DNA content. Cytometry 2000; 39:141-50.

Crissman HA, Hofland MH, Stevenson AP, Wilder ME, Tobey R. Supravital cell staining with Hoechst 33342 and DiOC5(3) In Methods in Cell Biology 1990;33:89-95. Academic Press, New York.

Crissman HA, Steinkamp JA. Rapid simultaneous measurements of DNA, protein and cell volume in single cells from large mammalian cell populations. J Cell Biol 1973; 59:766.

Darzynkiewicz Z, Bruno S, Del Bino G, Gorczyca W, Hotz MA, Lassota $P$, Traganos F. Features of the apoptotic cells measured by flow cytometry. Cytometry 1992;13:795-808.

Donahue CJ, Santoro M, Hupe D, Jones JM, Pollok B, Heim R, Giegel D. Correlating cell cycle with apoptosis in a cell line expressing a tandem green fluorescent protein substrate specific for group II caspases. Cytometry 2001;45:225-34.

Douglas RS, Pletcher $\mathrm{CH}$, Nowell PC, Moore JS. Novel approach for simultaneous evaluation of cell phenotype, apoptosis and cell cycle using multiparameter flow cytometry. Cytometry 1998;32:57-65.

Ellwart JW, Dörmer P. Vitality measurement using spectrum shift in Hoechst 33342 stained cells. Cytometry 1990;11:239-43.

Erba E, Ubezio P, Broggini M, Ponti, M, D'Incalci, M. DNA damage, cytotoxic effect and cell-cycle perturbation of Hoechst 33342 on L1210 cells in vitro. Cytometry 1988;9:1-6.

Frey T. Nucleic acid dyes for detection of apoptosis in live cells Cytometry 1995;21:265-74.

Kiechle FL, Zhang X. Apoptosis: biochemical aspects and clinical implications. Clin Chim. Acta 2002;326:27-45.

Loken MR Simultaneous quantitation of Hoechst 33342 and immunofluorescence on viable cells using a fluorescence activated cell sorter. Cytometry 1980;1:136-42.

Maciorowski Z, Delic J, Padoy E, Klijanienko J, Dubray B, Cosset JM, Dumont J, Magdelenat H, Vielh P. Comparative analysis of apoptosis measured by Hoechst and flow cytometry in non-hodgkin's limphomas. Cytometry 1998;32:44-50.

Mazzini G, Giordano P, Montecucco CM, Riccardi A. A rapid cytofluorometric method for quantitative DNA determination on fixed smears. Histochem J 1980;12:153-68.

Myc A, Traganos F, Lara J, Melamed MR, Darzynkiewicz Z. DNA stainability in aneuploid breast tumors: Comparison of four DNA fluorochromes differing in binding properties. Cytometry 1992;13:38994.
Necchi D. Apoptosis: cellular features and detection techniques in situ. Apoptosis, The Bender MedSystem Newsletter 2000; Issue 3.

Ormerod MG Investigating the relationship between the cell cycle and apoptosis using flow cytometry. J Immunol Methods 2002;265:7380.

Ormerod MG, Sun XM, Snowden RT, Davies R, Fearnhead H, Cohen $\mathrm{GM}$. Increased membrane permeability of apoptotic thymocytes: a flow cytometric study. Cytometry 1993; 14:595-602.

Pollice A, McCoy JP; Jr. Shackney SE, Smith CA, Agarwal J, Burholt DR, Janocko LE, Hornicek FJ, Singh SG Hartsock R. Sequential paraformaldehyde and methanol fixation for simultaneous flow cytometric analysis of DNA, cell surface proteins, and intracellular proteins. Cytometry 1992; 13:432-44.

Schmid I, Ferbas J, Uittenbogaart CH, Giorgi JV Flow cytometric analysis of live cell proliferation and phenotype in populations with low viability. Cytometry 1999;35:64-74.

Schmid I, Krall WJ, Uittenbogaart CH, Braun J, Giorgi JV. Dead cell discrimination with 7-amino-actinomycin $D$ in combination with dual color immunofluorescence in single laser flow cytometry. Cytometry 1992;13:204-8.

Siemann DW, Keng PC Cell cycle specific toxicity of the Hoechst 33342 stain in untreated or irradiated murine tumor cells. Cancer Res 1986;46:3556-9.

Smetana K., Hrkal Z. Nucleoli in large (giant) bi- and multinucleate cells after apoptosis-inducing photodynamic treatment. Eur J Histochem 2003; 47:39-44.

Soldani C, Bottone MG, Pellicciari C, Scovassi AI. Two-color fluorescence detection of Poly (ADP-Ribose) Polymerase-1 (PARP-1) cleavage and DNA strand breaks in etoposide-induced apoptotic cells. Eur J Histochem 2001;45:389-92.

Stöhr M, Vogt-Schaden M. A new dual staining technique for simultaneous flow cytometric DNA analysis of living and dead cells. In: Laerum OD, Lindmo T, Thorud E. eds. Flow cytometry IV. Universitetsforlaget, Bergen, 1980; pp. 96-99.

Telford WG, King LE, Fraker PJ. Comparative evaluation of several DNA binding dyes in the detection of apoptosis-associated chromatin degradation by flow cytometry. Cytometry 1992;13:137-43.

Uva BM, Masini MA, Sturla M, Bruzzone F, Giuliani M, Tagliafierro G, Strollo F. Microgravity-induced apoptosis in cultured glial cells. Eur J Histochem 2002;46: 209-14.

van Engelans M, Nieland LJW, Ramaeckers FCS, Schutte B, Reutelingsperger CPM Annexin $\mathrm{V}$ affinity assay: a review on an apoptosis detection system based on phosphatidylserine exposure. Cytometry 1998;31:1-9.

Vermes I, Haanen C, Reutelingsperger C. Flow cytometry of apoptotic cell death. J Immunol Methods 2000;243:167-90.

Weber GF, Daley J, Kraeft SK, Chen LB, Canton H. Measurement of apoptosis in heterogenous cell populations. Cytometry 1997;27: 13644.

Willingham MC Cytochemical methods for the detection of apoptosis. J Histochem Cytochem 1999;47: 1101-9.

Zamai L, Bareggi R, Santavenere E, Vitale M. Subtraction of autofluorescent dead cells from the lymphocyte flow cytometric binding assay. Cytometry 1993;14:951-4.

Zamai L, Falcieri E, Marhefka G, Vitale M. Supravital exposure to propidium iodide identifies apoptotic cells in the absence of nucleosomal DNA fragmentation. Cytometry 1996;23:303-11. 